\title{
Classical Glioblastoma
}

National Cancer Institute

\section{Source}

National Cancer Institute. Classical Glioblastoma. NCI Thesaurus. Code C111694.

A molecular subtype of glioblastoma characterized by lack of p53 mutations,

chromosome 7 amplifications or deletions, and high levels of EGFR amplification. 